\title{
Severe Cutaneous Adverse Drug Reactions Associated with Allopurinol: An Analysis of Spontaneous Reporting System in Southern Italy
}

\author{
Cristina Scavone ${ }^{1}$. Cristina Di Mauro ${ }^{1} \cdot$ Rosanna Ruggiero $^{1} \cdot$ Francesca Futura Bernardi $^{1,2} \cdot$ Ugo Trama $^{2}$. \\ Maria Luisa Aiezza ${ }^{3}$. Concetta Rafaniello ${ }^{1}$. Annalisa Capuano ${ }^{1}$
}

Published online: 17 December 2019

(c) The Author(s) 2019

\begin{abstract}
Background Allopurinol can induce severe cutaneous adverse reactions (SCARs), including Drug Reaction with Eosinophilia and Systemic Symptoms (DRESS) syndrome, Stevens-Johnson syndrome (SJS) and toxic epidermal necrolysis (TEN). Aims and Methods We analyzed the Individual Case Safety Reports (ICSRs) sent from January 2001 until April 2019 to the Campania regional Center of Pharmacovigilance (Southern Italy) that reported allopurinol as suspected, with a focus on those reporting at least one serious cutaneous adverse drug reaction (ADR). This study was aimed to describe the main characteristics of all ADRs associated with allopurinol, analyze the proportion of serious cutaneous ADRs of total ICSRs related to allopurinol and to compare the main features (age, sex, seriousness and outcome) of ICSRs that reported serious cutaneous ADRs with those that did not.

Results The Campania regional Center of Pharmacovigilance received 108 ICSRs that reported allopurinol as suspected. ADRs occurred more frequently in the elderly (median age: 71 years) and female patients (53.7\%). Fifty-seven percent of all ADRs were classified as serious and 58\% had a favorable outcome. Fifty-six ICSRs reported at least one serious cutaneous ADR; among these ICSRs, 37 cases of SCARs were found [DRESS syndrome $(n=3 ; 5.4 \%)$, SJS $(n=8 ; 14.3 \%)$ and TEN $(n=26 ; 46.4 \%)$ ]. Serious cutaneous ADRs commonly occurred in the elderly (median age: 73 years) and female patients $(62.5 \%)$. They frequently required hospitalization (75\%) and had an unfavorable outcome (46\%). No statistically significant differences were found between ICSRs that reported serious cutaneous ADRs and ICSRs that did not report serious cutaneous ADRs except for the seriousness degree "Hospitalization or its prolongation" and the outcome degrees "Unfavorable" and "Favorable".

Conclusion This study found that 52\% (56/108) of all ICSRs having allopurinol as a suspected drug were serious cutaneous ADRs. Serious cutaneous ADRs associated with allopurinol frequently required hospitalization or prolonged hospitalization, and almost half had an unfavorable outcome.
\end{abstract}

\section{Keypoints}

Concetta Rafaniello and Annalisa Capuano are both lead authors.

Annalisa Capuano

annalisa.capuano@unicampania.it

1 Section of Pharmacology “L. Donatelli”, Department of Experimental Medicine, Campania Regional Centre for Pharmacovigilance and Pharmacoepidemiology, University of Campania "Luigi Vanvitelli", Via Costantinopoli 16, 80138 Naples, Italy

2 Regional Pharmaceutical Unit, Naples, Campania Region, Italy

3 Complex Operating Unit of Pharmacy, AORN A Cardarelli, Naples, Italy
Allopurinol carries a well-known risk of serious cutaneous ADRs.

During almost 20 years of spontaneous reporting activities in Italy, 108 ICSRs that reported allopurinol as suspected were sent to the Campania regional Center of Pharmacovigilance.

Fifty-six cases of serious cutaneous ADRs associated with allopurinol were found. Compared to ICSRs reporting other ADRs, serious cutaneous ADRs had an unfavorable outcome ( $8 \%$ vs. $46 \%$; statistically significant difference). 


\section{Introduction}

Allopurinol, an inhibitor of xanthine oxidase, prevents the oxidation of xanthine to uric acid. It is indicated for the treatment of clinical manifestations of hyperuricemia and its complications, including chronic gout, uric acid lithiasis and acute uric acid nephropathy [1]. Hyperuricemia may have several underlying causes; the most common are diseases that induce an overproduction of urate or its inefficient excretion by the kidneys (i.e. myeloproliferative disorders, exfoliative psoriasis or renal insufficiency) and medications that impair the renal urate clearance. Indeed, several studies showed that patients with moderate-high levels of uric acid were likely to use a larger number of antihypertensive and diuretic drugs compared to patients with normal uric acid levels [2-6].

During the treatment with allopurinol, patients may commonly experience rash, gout flares, gastrointestinal symptoms, elevation in hepatic enzymes, hematologic abnormalities and drowsiness [7]. In addition to these common adverse drug reactions (ADRs), allopurinol can also induce serious cutaneous ADRs, including severe cutaneous adverse reactions (SCARs) [8-11]. SCARs are defined as hypersensitivity reactions that are severe, unpredictable, and drug induced [12, 13]. Several types of SCARs were recognized, including Drug Reaction with Eosinophilia and Systemic Symptoms (DRESS) syndrome, Stevens-Johnson syndrome (SJS), toxic epidermal necrolysis (TEN), acute generalized exanthematous pustulosis (AGEP), and generalized bullous fixed drug eruptions (GBFDE). Currently it is known that allopurinol can induce the occurrence of DRESS, SJS and TEN [14-17]. DRESS syndrome is a severe ADR, potentially life-threatening, presenting with skin eruption, hematological abnormalities (eosinophilia, atypical lymphocytosis) and multi-organ involvement [18]. TEN and SJS represent two of the most severe cutaneous ADRs associated with high morbidity and with mortality rates that range from 1 to $5 \%$ for SJS and $25-35 \%$ for TEN [19]. According to Dodiuk-Gad RP et al., these conditions represent different degrees of the same type of severe cutaneous ADR [20]. Indeed, TEN and SJS share common clinical manifestations, including flu-like symptoms (malaise, fever, anorexia), cutaneous and mucosal involvement, which can result in skin exfoliation, possible sepsis and death. SJS and TEN differ in the extent of detachment, which is usually limited in SJS ( $<10 \%$ body surface area) while it is more widespread in TEN (>30\%) [21-23]. According to the information reported in the Summary of Products Characteristics (SPC) of allopurinol, the association of this drug with ampicillin/amoxicillin or thiazide diuretics increases the risk of SCARs [1]. Furthermore, given that SCARs have been shown to occur more frequently in HLA-B*5801 positive patients (1-2\% of Caucasian population), the screening for HLA-B*5801 is recommended before the initiation of the therapy with allopurinol [1].
In conclusion, according to literature: cutaneous ADRs are responsible for about $2 \%$ of hospital admissions; SCARs are of major concern because of high mortality and morbidity rates; SCARs still represent a challenge for healthcare providers mainly due to absence of accurate and standardized biomarkers that delays the diagnosis; hypouricaemic drugs represent one of the drug classes most frequently associated with serious cutaneous ADRs (including SCARs) [24-28]. Based on that, we carried out a study evaluating the safety profile of allopurinol, with a focus on serious cutaneous ADRs (including SCARs), in real life conditions in the Campania Region using data from the Italian spontaneous reporting system.

We analyzed Individual Case Safety Reports (ICSRs) that reported allopurinol as suspected drug in order to: perform a descriptive analysis of all ADRs; describe the proportion of serious cutaneous ADRs (including SCARs) of total ICSRs related to allopurinol; compare the main characteristics of patients (age and sex) who experienced serious cutaneous ADRs with those that presented other ADRs after allopurinol administration; compare the main features of serious cutaneous ADRs with other ADRs in term of seriousness and outcome; provide an overview of SCAR cases.

\section{Methods}

\subsection{Data Source}

The Italian spontaneous reporting system is based on a national pharmacovigilance database (Rete Nazionale di Farmacovigilanza-RNF), which was established by the Italian regulatory agency (Agenzia Italiana del FarmacoAIFA) in 2001. According to the national rules, each Italian region shall carry out post-marketing surveillance activities, including those related to the collection and analysis of ICSRs, through a regional Center of Pharmacovigilance. The Campania regional Center of Pharmacovigilance was activated with the implementation of Legislative Decree No. 95 of 2003 and the Resolution No. 2530 of August 6th 2003 [29].

\subsection{Data Analysis}

ICSRs received by the Campania regional Center of Pharmacovigilance from January 1st 2001 to April 15th 2019 that reported allopurinol as suspected were evaluated. Then we focused our analysis on ICSRs that reported at least one serious cutaneous ADR, defined by the SOC "Skin and subcutaneous tissue disorders" and by a seriousness degree equal to serious (serious-death"; "serious-hospitalization or its prolongation"; "serious-persistent or significant disability or incapacity"; "serious-life-threatening"; 
"serious-congenital anomaly/birth defect"; "seriousclinically relevant"). Among those ICSRs we searched for cases of DRESS syndrome, SJS, TEN, AGEP and GBFDE.

We performed a descriptive analysis of all ICSRs (those that reported serious cutaneous ADRs and those that did not) stratifying by median age (IQR), sex, seriousness, and outcome. Only for ICSRs reporting SCARs we performed a descriptive analysis in terms of time to event (TTE), types of suspected drugs other than allopurinol, concomitant medications, therapeutic indication, source of report (healthcare professional, patient/citizen, pharmaceutical company), and causality assessment. As described in the ICH-E2A (Good Pharmacovigilance Practices Annex IV), the seriousness of ADRs was categorized as: serious-death; serious-hospitalization or its prolongation; serious-persistent or significant disability or incapacity; serious-life-threat; serious-congenital anomaly/birth defect; serious-clinically relevant; not serious; not defined [30, 31]. The outcome was categorized as favorable (completely resolved or improved) or unfavorable (resolved with sequelae, unchanged or death).

All the Italian Regional Centers of Pharmacovigilance (including the Campania one) use the Naranjo algorithm in order to establish the strength of the relationship between a suspected drug and ADR(s). Therefore, as part of the routine pharmacovigilance activities of the Campania regional Center of Pharmacovigilance, the Naranjo algorithm was applied for ICSRs reporting serious cutaneous ADRs evaluated in this study. All scores ranged between possible and certain reports were considered reasonable for causality.

Safety data deriving from the Italian spontaneous reporting system are anonymous and in compliance with the ethical standard. Therefore, no further ethical measures were required.

\subsection{Statistical Analysis}

Chi-squared analysis with Mann-Whitney $U$ test or Fisher exact test, where appropriate, was employed to examine differences between ICSRs that reported serious cutaneous ADRs and ICSRs that reported other ADRs, with a 5\% significance level. Data were analyzed using the Microsoft Excel program.

\section{Results}

\subsection{Overall Results}

From January 1st, 2001 until April 15th, 2019 the Campania regional Center of Pharmacovigilance received 108 ICSRs that reported allopurinol as suspected. ADRs mainly occurred in elderly patients (median age: 71 years; IQR: 61-80) and in a slightly higher percentage of women compared to men ( $53.7 \%$ vs. $45.4 \%)$. Overall, $57 \%$ of ICSRs reported ADRs that were considered as serious and $40 \%$ reported ADRs that were classified as not serious. The outcome was favorable in $58 \%$ of cases and unfavorable in $28 \%$ (Table 1).

Out of 108 ICSRs that reported allopurinol as suspected, 56 reported serious cutaneous ADRs (including 37 cases of SCARs) (Tables 1 and 2, Fig. 1). Compared to ICSRs not reporting serious cutaneous ADRs, the median age of patients who experienced a serious cutaneous ADR was similar (68 vs. 73 ; difference not statistically significant). Furthermore, while serious cutaneous ADRs occurred more frequently in women compared to men $(62.5 \%$ vs. $35.7 \%)$, other ADRs were more common in males ( $56 \%$ vs. $44 \%$; difference not statistically significant). Furthermore, we found statistically significant differences in the rate of unfavorable and favorable outcomes of serious cutaneous ADRs versus other ADRs ( $46 \%$ vs. $8 \%$ and $41 \%$ vs. $77 \%$, respectively; $p<0.001$ for both) (Table 1). All ICSRs reporting serious cutaneous ADRs came from healthcare professionals (data not shown).

According to the therapeutic indications reported in ICSRs reporting serious cutaneous ADRs, allopurinol was used for the treatment of hyperuricemia $(n=36 ; 64.3 \%)$, gout $(n=8 ; 14.3 \%)$ or other therapeutic indications, including renal failure, hemolytic anemia and hyperazotemia $(n=8 ; 14.3 \%)$; in 4 ICSRs $(7.1 \%)$ the therapeutic indication was not reported (data not shown). Allopurinol was the only medication indicated as suspected in 57\% of ICSRs reporting serious cutaneous ADRs; in the remaining ones, other medications were instead reported, including antihypertensive drugs (ACE inhibitors, beta-blockers, calcium channel blockers, loop diuretics, and therapeutic associations with hydrochlorothiazide), antibiotics (amoxicillin and clavulanic acid, ceftriaxone, levofloxacin), non-steroidal anti-inflammatory drugs (NSAIDs—diclofenac, ketorolac, nimesulide), antiplatelet therapy, and anti-cancer drugs (data not shown). Concomitant medications were reported in $89 \%$ of ICSRs reporting serious cutaneous ADRs; these were mainly represented by antihypertensive, lipid lowering drugs and protonpump inhibitors (data not shown).

\subsection{SCAR Cases}

Out of 56 ICSRs reporting serious cutaneous ADRs, 34\% $(n=19)$ referred to ADRs that were represented by cases of desquamative erythema, rash, skin swelling, and urticaria (data not shown).

The remaining 66\% $(n=37)$ of serious cutaneous ADRs referred to cases of SCARs [DRESS syndrome $(n=3 ; 5.4 \%)$, SJS $(n=8 ; 14.3 \%)$ and TEN $(n=26 ; 46.4 \%)]$ (Fig. 1 and Table 2). No cases of AGEP and GBFDE were reported to the Campania regional Center of Pharmacovigilance. 
Table 1 Demographic and clinical characteristics of individual case safety reports having allopurinol as suspected drug sent through the Campania Region spontaneous reporting system from January 2001 to April 2019

\begin{tabular}{|c|c|c|c|c|c|}
\hline Variable & Level & All ICSRs $(n=108)$ & $\begin{array}{l}\text { ICSRs reporting serious } \\
\text { cutaneous ADRs (including } \\
\text { SCARs) }(n=56)\end{array}$ & $\begin{array}{l}\text { ICSRs not reporting } \\
\text { serious cutaneous ADRs } \\
(n=52)\end{array}$ & $p$ value $(<0.05)$ \\
\hline Age, years & Median (IQR) & $71(61-80)$ & $73(63.5-80)$ & $68(56.25-79)$ & $0.095^{\mathrm{b}}$ \\
\hline \multirow[t]{3}{*}{ Sex } & Female & $58(53.7)$ & $35(62.5)$ & $23(44)$ & $0.054^{\mathrm{c}}$ \\
\hline & Male & $49(45.4)$ & $20(35.7)$ & $29(56)$ & \\
\hline & Missing & $1(0.9)$ & $1(1.8)$ & - & \\
\hline \multirow[t]{6}{*}{ Seriousness } & $\begin{array}{l}\text { Hospitalization or its } \\
\text { prolongation }^{\text {a }}\end{array}$ & $43(40)$ & $42(75)$ & $1(2)$ & $<0.001^{\mathrm{c}}$ \\
\hline & Clinically relevant $^{\mathrm{a}}$ & $10(9)$ & $5(9)$ & $5(10)$ & 0.902 \\
\hline & Death & $6(5)$ & $6(11)$ & - & - \\
\hline & Life-threatening $^{\mathrm{a}}$ & $3(3)$ & $3(5)$ & - & - \\
\hline & Not serious & $43(40)$ & - & $43(82)$ & - \\
\hline & Not defined & $3(3)$ & - & $3(6)$ & - \\
\hline \multirow[t]{3}{*}{ Outcome } & $\begin{array}{l}\text { Unfavorable (death or } \\
\text { unchanged) }\end{array}$ & $30(28)$ & $26(46)$ & $4(8)$ & $<0.001$ \\
\hline & $\begin{array}{l}\text { Favorable (completely } \\
\text { resolved or improved) }\end{array}$ & $63(58)$ & $23(41)$ & $40(77)$ & $<0.001$ \\
\hline & Not available & $15(14)$ & $7(12)$ & $8(15)$ & - \\
\hline
\end{tabular}

Values are $n(\%)$ unless otherwise stated

$A D R s$ adverse drug reactions, ICSRs individual case safety reports, IQR interquartile range, SCARS severe cutaneous adverse reactions

${ }^{\text {a }}$ Some of these cases may have resulted in patient's death

${ }^{\mathrm{b}}$ Mann-Whitney U test

${ }^{\mathrm{c}}$ Fisher exact test

Three cases of DRESS syndrome associated with allopurinol were sent to the Campania Regional Center of Pharmacovigilance. Patients' age was 82, 80 and 57 years for case $n .1,2$ and 3, respectively. The TTE was 3, 40 and 49 days for case $n$. 1, 2 and 3, respectively. The outcome of the ADR was unfavorable for cases n. 1 and 2. Levofloxacin and cholecalciferol were indicated as second suspected drugs in case $\mathrm{n} .2$ and 3. All patients were concomitantly receiving at least 3 medications. The sex ratio (male-to-female) for DRESS cases was 2:0 (sex was not reported in one case).

Eight cases of SJS associated with allopurinol were received by our Center. Patients' age ranged from 38 to 84 years. Except for the case n. 8, all SJS cases occurred within the first 4 weeks from the beginning of the allopurinol therapy. The outcome was favorable in 3 cases, unfavorable in 3 cases and not available for the remaining 2 cases. Cases n. 2, 4 and 8 had further suspected drugs, including antibiotics. All cases, apart from cases n. 3 and 5 , reported at least 3 concomitant medications. The sex ratio (male-to-female) for SJS cases was 0.6:1.

Finally, we received twenty-six cases of TEN associated with allopurinol. Patients' age ranged from 55 to 86 years. TTE was extremely variable, ranging from 3 days (case $n$. 1) to 4380 days (case $n$. 4) from the beginning of the allopurinol therapy. The occurrence of the ADR was followed by the patient's death in 13 cases. Fourteen ICSRs reported further suspected drugs, including antibiotics, beta-blockers and NSAIDs. All cases, except for cases $n .1$ and 15, reported at least one concomitant medication. The sex ratio (male-tofemale) for TEN cases was 0.3:1.

Apart from SJS cases $n .3$ and 5 and TEN cases $n .1,7$ and 17 (for which the causality assessment resulted in probable), the causality assessment resulted in possible in all ICSRs (Table 2).

\section{Discussion}

\subsection{Overall Results}

In our study ADRs associated with allopurinol mainly occurred in elderly patients. This is not surprising if we consider that diseases for which allopurinol is indicated (mainly gout and hyperuricemia) usually affect patients older than 40 years of age. Together with ageing, male sex, metabolic syndrome and medications are among risk factors leading to the occurrence of these clinical conditions [32,33]. Whilst men have an increased risk of gout and hyperuricemia and, therefore, are more prone to be treated with allopurinol, we found that ADRs, especially serious cutaneous ADRs, were more common in women. This is not surprising because 
Table 2 Individual case safety reports related to DRESS, SJS and TEN cases having allopurinol as suspected drug and sent through Campania Region spontaneous reporting system from January 2001 to April 2019

\begin{tabular}{|c|c|c|c|c|c|c|c|}
\hline Case $n$. & Age (years) & $\begin{array}{l}\text { TTE } \\
\text { (days) }\end{array}$ & Outcome & $\begin{array}{l}\text { Therapeutic indication of } \\
\text { allopurinol }\end{array}$ & $\begin{array}{l}\text { Suspected drug(s) other than } \\
\text { allopurinol }\end{array}$ & $\begin{array}{l}\text { Number of } \\
\text { concomitant } \\
\text { drugs }\end{array}$ & $\begin{array}{l}\text { Causality } \\
\text { assessment }\end{array}$ \\
\hline
\end{tabular}

\section{DRESS Syndrome}

\begin{tabular}{|c|c|c|c|c|}
\hline 1 & 82 & 3 & Unfavorable-U & Hyperuricemia \\
\hline 2 & 80 & 40 & Unfavorable-U & Gout \\
\hline 3 & 57 & 49 & Favorable -I & Hyperuricemia \\
\hline \multicolumn{5}{|c|}{ SJS } \\
\hline 1 & 67 & 4 & Favorable-CR & Hyperuricemia \\
\hline 2 & 84 & 10 & Favorable-I & Hyperuricemia \\
\hline 3 & 38 & 12 & Unfavorable-U & Hyperuricemia \\
\hline 4 & 73 & 13 & Unfavorable-U & Hyperuricemia \\
\hline 5 & 57 & 16 & Unfavorable-U & Hyperuricemia \\
\hline 6 & 69 & 19 & Favorable-I & Hyperuricemia \\
\hline 7 & 81 & 26 & NA & Hyperuricemia \\
\hline 8 & 81 & 4288 & NA & $\begin{array}{l}\text { Other therapeutic indica- } \\
\text { tions }\end{array}$ \\
\hline
\end{tabular}

$\begin{array}{lll}- & 3 & \text { Possible } \\ \text { Levofloxacin } & 7 & \text { Possible } \\ \text { Cholecalciferol } & 4 & \text { Possible } \\ & & \\ - & 6 & \text { Possible } \\ \text { Piperacillin } & 9 & \text { Possible } \\ - & 0 & \text { Probable } \\ \text { Flu vaccine } & 4 & \text { Possible } \\ - & 0 & \text { Probable } \\ - & 3 & \text { Possible } \\ - & 4 & \text { Possible } \\ \text { Amoxicillin and clavulanic acid } & 7 & \text { Possible }\end{array}$

\section{TEN}

$\begin{array}{lllll}1 & 78 & 3 & \text { Favorable-I } & \text { Hyperuricemia } \\ 2 & 68 & 60 & \text { Unfavorable-D } & \text { Hyperuricemia } \\ 3 & 67 & 30 & \text { Unfavorable-U } & \text { Other therapeutic indica- } \\ \text { tions }\end{array}$

\begin{tabular}{|c|c|c|}
\hline- & 0 & Probable \\
\hline $\begin{array}{l}\text { Bortezomib, sulfamethoxazole } \\
\text { and trimethoprim, acyclovir }\end{array}$ & 2 & Possible \\
\hline Rituximab & 4 & Possible \\
\hline Amoxicillin and clavulanic acid & 12 & Possible \\
\hline- & 5 & Possible \\
\hline Ceftriaxone, levofloxacin & 5 & Possible \\
\hline- & 4 & Probable \\
\hline- & 1 & Possible \\
\hline- & 7 & Possible \\
\hline Carvedilol & 4 & Possible \\
\hline Carvedilol & 3 & Possible \\
\hline- & 8 & Possible \\
\hline Ciprofloxacin & 3 & Possible \\
\hline- & 1 & Possible \\
\hline Diclofenac & 0 & Possible \\
\hline- & 4 & Possible \\
\hline Macrogol & 3 & Probable \\
\hline- & 4 & Possible \\
\hline Ceftriaxone & 10 & Possible \\
\hline Ketorolac & 7 & Possible \\
\hline- & 3 & Possible \\
\hline Bortezomib & 8 & Possible \\
\hline Brentuximab vedotin & 6 & Possible \\
\hline- & 9 & Possible \\
\hline Nimesulide & 1 & Possible \\
\hline- & 11 & Possible \\
\hline
\end{tabular}

DRESS Drug Reaction with Eosinophilia and Systemic Symptoms, Favorable CR completely resolved, Favorable I improved, NA not available, SJS Stevens-Johnson syndrome, TEN toxic epidermal necrolysis, TTE time to event, Unfavorable D death, Unfavorable U unchanged

Other therapeutic indications: these conditions included renal failure, hemolytic anemia and hyperazotemia 


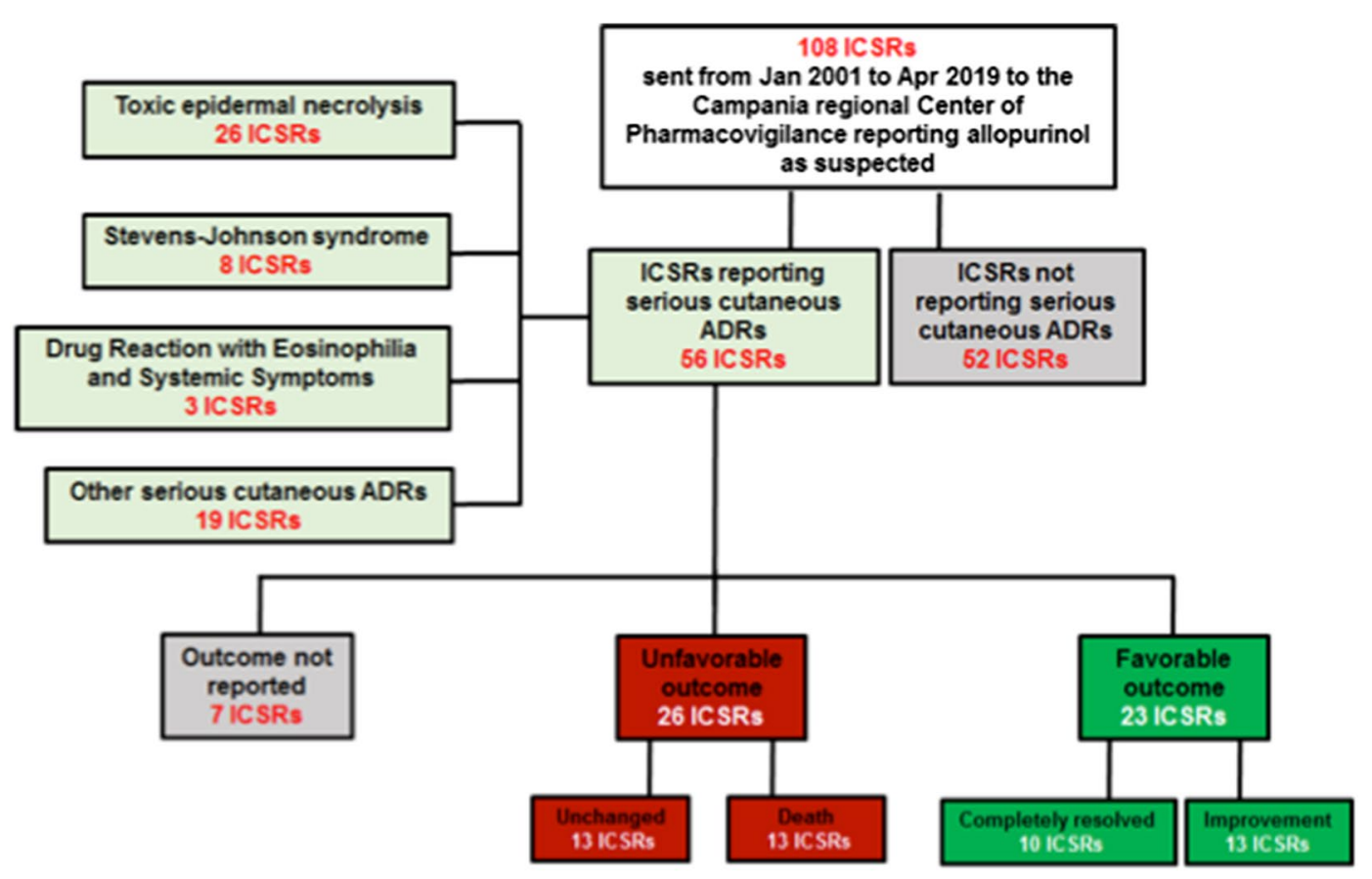

Fig. 1 Flowchart of ICSRs related to serious cutaneous ADRs associated with allopurinol in the Campania Region. The number of cases that resulted in death referred to the outcome of the ADR; therefore,

females seem to be more likely at risk to experience ADRs due to sex-specific differences in the pharmacokinetics and pharmacodynamics of drugs [34-37]. Furthermore, literature data confirm that both SJS and TEN could occur at any age, but appear to be more prevalent in adults, with a slight predominance in women $[38,39]$. In line with our findings, the results of two European studies based on the Portuguese Central Health System Administration and on the Spanish Pharmacovigilance database found that both SJS and TEN were more common in female patients [27, 40]. In our study, among patients who experienced DRESS syndrome, 2 were males while for one case the sex was not reported. Even though a sex predominance among DRESS cases of our study cannot be established, due to the very limited number of cases, the results of a recent retrospective study based on data from electronic medical records for patients who developed drug-induced cutaneous ADRs between 2008 to 2018 showed a male preponderance in DRESS cases (12 cases in males vs. 7 cases in females) [41]. It must be stressed, however, that a study carried out by Agier et al. using data from the French Pharmacovigilance Database revealed that DRESS occurred more commonly in women with a sex ratio (male-to-female) equal to 0.9:1 [42]. Moreover, few case reports reported the occurrence of DRESS syndrome in female patients treated with allopurinol [43-46].

In our study, ADRs were mainly classified as serious (57\%). Literature data seem to suggest that serious ADRs this number $(n=13)$ is higher compared to the number reported in Table 1 since 7 ICSRs that led to patient's hospitalization or its prolongation resulted in patient's death

associated with allopurinol are rare [47]. Compared to all ADRs associated with allopurinol, serious cutaneous ADRs more commonly presented unfavorable outcomes (46\%). In line with our results, Kim et al. [48] showed that although the incidence of hospitalization due to the occurrence of SCARs is $<1 / 1000$ person-year, the in-hospital mortality is around $27 \%$. Further studies confirmed that SCARs frequently led to patients' hospitalization and unfavorable outcomes [49-52] and that these ADRs were often acute emergencies [53]. However, a reporting bias cannot be ruled out. Indeed, all serious cutaneous ADRs in our study were reported by healthcare professionals and, according to the results of a systematic review of Inácio et al. healthcare professionals seem to be especially prone to report more serious ADRs that result in hospitalization, are life-threatening or result in death [54].

Among cases of serious cutaneous ADRs, allopurinol was mainly used for the treatment of hyperuricemia and patients were frequently receiving other medications, including antihypertensive drugs. It is well known that antihypertensive medications may induce both hyperuricemia and gout as a iatrogenic effect [55-57].

According to our results, $43 \%$ of ICSRs reporting serious cutaneous ADRs reported other suspected drugs besides allopurinol and $89 \%$ reported concomitant medications. These data are not surprising if we consider that our patients that experienced SCARs were mainly elders and that this 
population shows higher prevalence of chronic diseases leading to the complex polypharmacy [58].

\subsection{SCAR Cases}

Among 56 ICSRs reporting serious cutaneous ADRs, we have found 37 cases of SCARs and 19 serious cutaneous ADRs that were mainly represented by desquamative erythema, rash and urticaria. In line with our results, Tsai TF et al. showed that the most common ADR associated with allopurinol is skin maculopapular eruption that occurs in almost $1.5 \%$ of treated patients $[9,10]$. Similarly, allopurinol was identified as the suspect drug in 84 cutaneous ADRs, which mainly included cases of maculopapular eruptions, SJS/TEN, vasculitis, DRESS syndrome, AGEP, Pityriasis rosea-like eruption, lichenoid dermatitis, fixed drug eruption, and erythroderma, at one Dermatology Department in Sardinia (Italian island) [59].

In our study 37 ICSRs reported cases of DRESS syndrome, SJS and TEN. Drug-induced SCARs are of major medical concern because they are associated with high morbidity and mortality. Literature documents that allopurinol carries a well-known risk of SCARs [47]. The incidence of SCARs in patients treated with allopurinol has been reported to be 0.69 (95\% CI $0.52,0.92)$ per 1000 person-years [48]. The incidence of SJS and TEN is estimated 1.0-6.0 per million and 0.4-1.2 per million, respectively, while the incidence of DRESS is still unclear, with an estimated overall population risk between 1 in 1000 and 1 in 10,000 drug exposures [60, 61].

Except for few cases, SCARs usually occurred within the first 2 months from the beginning of the allopurinol therapy. In line with our findings, literature data showed that the TTE for drug-induced DRESS syndrome, SJS or TEN is extremely variable, ranging from 10 days to 2 months [38, 39, 62]. Therefore, the risk of developing these ADRs after drug exposure appears to be the greatest during the initial weeks of treatment. A dose-dependent increase of the risk of SJS and TEN in patients taking $200 \mathrm{mg}$ or more of allopurinol per day was found $[63,64]$. Among our ICSRs, 4 cases (SJS case n. 8, and TEN cases $n .4,7$ and 8 ) had a TTE that exceeded 365 days indicating that even though SCARs usually develop within weeks or few months, longer delays may occur. To our knowledge, only one study reported a TTE that reach almost 2 years of treatment [65], but no explanation was found for such a long TTE. In our study, the majority of DRESS syndrome, SJS and TEN cases had an unfavorable outcome; in particular, out of 26 TEN cases, 13 resulted in patient's death (all patients were receiving other suspected and/or concomitant drugs). According to literature, SJS and TEN are the most common and lethal of all SCARs. Both conditions are associated with a mortality of up to $40 \%$ compared to $10 \%$ for DRESS [66]. Negative outcomes may result from clinical complications such as infections due to skin exfoliation or systemic organ injury. SCARs may permanently damage mucosa and skin; among survivors of SJS/TEN, 50\% have severe sequelae, including corneal scarring leading to visual impairment, perineal stricture, bronchiolitis, hair loss, and scarring [18, 19, 57, 67-69]. On the other hand, even though the outcome for DRESS syndrome is usually favorable after discontinuation of the suspect drug, full resolution may require at least 2 weeks and the prognosis depends on the severity of organ involvement $[16,17]$. Furthermore, since most of our patients were elderly and were receiving medications other than allopurinol, the fatal outcomes are not surprising, considering the significant impact of SCARs on general health status of frail patients. Accordingly, a strong correlation between mortality due to SJS and TEN, patient's age and the severity of the disease has been reported [70]. Similarly, a retrospective cross-sectional study, which involved patients with SJS and TEN, showed that the fatal outcome occurred in almost $67 \%$ of elderly patients [71]. A correlation between disease' severity and age was found for DRESS syndrome as well. According to the results of a systematic review, patients with severe DRESS tended to be older than those recovering from DRESS [18]. Lastly, most of case reports and case series on patients presenting SJS and TEN reported a fatal outcome [72-75]. Of note, in our study two of the fatal TEN occurred in patients who were concomitantly treated with bortezomib, which itself is associated with the onset of TEN [76]. Lastly, the majority of ICSRs that we have analyzed reported other suspected and concomitant medications, including sulfonamides, anti-epileptic, anticancer drugs, and NSAIDs, most of which have been identified as causative agents in developing SCARs. Also, the hypothetical role of concomitant medications in the development of hyperuricemia cannot be ruled out. Moreover, the concomitant administration of 2 or more high-risk drugs, such as those able to induce T cell-dependent reactions (like levofloxacin), can increase the likelihood of developing SCARs [77, 78].

\section{Study Strengths and Limitations}

It is well known that post-marketing surveillance has several limitations. Our study was based on data from the spontaneous reporting system. Spontaneous reports from patients and physicians are voluntary; thus, they can be affected by the so-called underreporting that is significant and widespread. In addition, data collected from spontaneous reporting systems could be incomplete and incorrect. For instance, an error in reporting allopurinol treatment interval and/or date of ADR occurrence (both used for the calculation of the TTE) cannot be ruled out. Three main limitations strictly related to our study were the clinical setting, the type of 
ADRs and the seriousness degree. First, some authors have argued that the therapy with allopurinol is frequently unnecessary based on current guidelines for the treatment of asymptomatic hyperuricemia and gout [79]. Unfortunately, the lack of access to patient's clinical data and impossibility to verify uricemia precluded from establishing the appropriateness of allopurinol prescription. Second, our study was focused on SCARs, whose diagnosis is complicated by the existence of overlap syndromes, characterized by the coexistence of features from different entities. Third, a reporting bias may have affected the seriousness degree of SCARs; indeed, all SCARs in our study were reported by healthcare professionals and, as we previously said, these reporters seem to be inclined to report serious ADRs.

Notwithstanding these limitations, two main important advantages of surveillance system can be identified: first, it guarantees ongoing surveillance of all patients and medicines and, second, it is relatively inexpensive. In recent years, thanks to the efforts of regulatory agencies, pharmaceutical industry and the medical community, the amount, quality and timely reporting of ADRs have greatly improved increasing the value of spontaneous reporting systems for post-marketing pharmacovigilance purposes.

\section{Conclusion}

We analyzed data from the Italian spontaneous reporting system from 2001 to 2019 in order to analyze ICSRs that reported allopurinol as suspected drug, with a focus on those reporting the association allopurinol/serious cutaneous ADRs (including SCARs). Our results demonstrated that ICSRs that reported serious cutaneous ADRs accounted for more than $50 \%$ of the total ICSRs related to allopurinol (56 out of a total of 108 ICSRs) but also that those ADRs, especially SCARs, commonly occurred in females and elderly patients (not statistically significant difference), frequently leading to unfavorable outcomes. Furthermore, those conditions frequently resulted in hospitalization and in some cases they led to the patient's death. Given the negative outcomes of SCARs and considering their high mortality rates, a rapid diagnosis with proper management of these clinical conditions is highly recommended.

Since ADRs still represent a common, often preventable, cause of illness, disability and even death, pharmacovigilance has to be considered as a key component of an effective drug regulation system, clinical practice and public health program in order to reduce harm to patients, improve public health and reduce healthcare costs.

Acknowledgements All authors approved the final version of the submitted manuscript.
Author Contributions CS, CDM, RR and FFB wrote the manuscript; UT, MLA, CR and AC made critical revisions to the manuscript; MLA, $\mathrm{CR}$ and $\mathrm{AC}$ designed the research; CS, CDM, RR and FFB performed the research; CS, CDM, RR and FFB analyzed the data.

\section{Compliance with Ethical Standards}

Funding No funding was received for this work.

Conflict of Interest CS, CDM, RR, FFB, UT, MLA, CR and AC report no conflicts of interest.

Open Access This article is licensed under a Creative Commons Attribution-NonCommercial 4.0 International License, which permits any non-commercial use, sharing, adaptation, distribution and reproduction in any medium or format, as long as you give appropriate credit to the original author(s) and the source, provide a link to the Creative Commons licence, and indicate if changes were made. The images or other third party material in this article are included in the article's Creative Commons licence, unless indicated otherwise in a credit line to the material. If material is not included in the article's Creative Commons licence and your intended use is not permitted by statutory regulation or exceeds the permitted use, you will need to obtain permission directly from the copyright holder. To view a copy of this licence, visit http://creativecommons.org/licenses/by-nc/4.0/.

\section{References}

1. Agenzia Italiana del Farmaco. Zyloric. Riassunto delle Caratteristiche del Prodotto. https://farmaci.agenziafarmaco.gov.it/aifa/ servlet/PdfDownloadServlet?pdfFileName=footer_007046_02125 9_RCP.pdf\&retry $=0 \& s y s=m 0 b 113$. Accessed 14 Mar 2019.

2. Chen XJ, Eirin A, Kane GC, Misra S, Textor SC, Lerman A, Lerman LO. Impact of Serum Uric Acid Levels on Outcomes following Renal Artery Revascularization in Patients with Renovascular Disease. Int J Hypertens. 2019;2019:3872065. https:// doi.org/10.1155/2019/3872065.

3. Qin T, Zhou X, Wang J, Wu X, Li Y, Wang L, Huang H, Li J. Hyperuricemia and the prognosis of hypertensive patients: a systematic review and meta-analysis. J Clin Hypertens (Greenwich). 2016;18:1268-78. https://doi.org/10.1111/jch.12855.

4. Weiner IM. Diuretics and other agents employed in the mobilization of edema fluid, Goodman and Gilman's the pharmacological basis of therapeutics. New York: McGraw-Hill; 1993.

5. Choi HK, Soriano LC, Zhang Y, Rodríguez LA. Antihypertensive drugs and risk of incident gout among patients with hypertension: population based case-control study. BMJ. 2012;344:d8190. https ://doi.org/10.1136/bmj.d8190.

6. Reyes AJ. Cardiovascular drugs and serum uric acid. Cardiovasc Drugs Ther. 2003;17:397-414.

7. Qurie A, Musa R. Allopurinol. [Updated 2018 Dec 14]. In: StatPearls [Internet]. Treasure Island (FL): StatPearls Publishing; 2019 Jan-. https://www.ncbi.nlm.nih.gov/books/NBK499942/ Accessed 14 Mar 2019.

8. Lin MS, Dai YS, Pwu RF, Chen YH, Chang NC. Risk estimates for drugs suspected of being associated with Stevens-Johnson syndrome and toxic epidermal necrolysis: a case-control study. Intern Med J. 2005;35:188-90.

9. Tsai TF, Yeh TY. Allopurinol in dermatology. Am J Clin Dermatol. 2010;11:225-32. 
10. Ramasamy SN, Korb-Wells CS, Kannangara DR, Smith MW, Wang N, Roberts DM, et al. Allopurinol hypersensitivity: a systematic review of all published cases, 1950-2012. Drug Saf. 2013;36:953-80.

11. Yang CY, Chen CH, Deng ST, Huang CS, Lin YJ, Chen YJ, et al. Allopurinol use and risk of fatal hypersensitivity reactions: a nationwide population-based study in Taiwan. JAMA Intern Med. 2015;175:1550-7.

12. Thong BY, Tan TC. Epidemiology and risk factors for drug allergy. Br J Clin Pharmacol. 2011;71(5):684-700. https://doi. org/10.1111/j.1365-2125.2010.03774.x (review).

13. Paulmann M, Mockenhaupt M. Severe drug-induced skin reactions: clinical features, diagnosis, etiology, and therapy. J Dtsch Dermatol Ges. 2015;13(7):625-45. https://doi.org/10.1111/ ddg. 12747.

14. Solak B, Dikicier BS, Kara RO, Erdem T. DRESS syndrome potentially induced by allopurinol and triggered by influenza vaccine. BMJ Case Rep. 2016. https://doi.org/10.1136/bcr2016-214563.

15. Halevy S, Ghislain PD, Mockenhaupt M, Fagot JP, Bouwes Bavinck JN, Sidoroff A, Naldi L, Dunant A, Viboud C, Roujeau JC, EuroSCAR Study Group. Allopurinol is the most common cause of Stevens-Johnson syndrome and toxic epidermal necrolysis in Europe and Israel. J Am Acad Dermatol. 2008;58:25-32.

16. Fritsch PO, Sidoroff A. Drug-induced Stevens-Johnson syndrome/toxic epidermal necrolysis. Am J Clin Dermatol. 2000;1:349-60.

17. Descamps V, Ranger-Rogez S. DRESS syndrome. Jt Bone Spine. 2014;81(1):15-21. https://doi.org/10.1016/j.jbspin.2013.05.002.

18. Cacoub P, Musette P, Descamps V, Meyer O, Speirs C, Finzi L, Roujeau JC. The DRESS syndrome: a literature review. Am J Med. 2011;124:588-97. https://doi.org/10.1016/j.amjme d.2011.01.017.

19. Harr T, French LE. Toxic epidermal necrolysis and StevensJohnson syndrome. Orphanet J Rare Dis. 2010;5:39. https://doi. org/10.1186/1750-1172-5-39.

20. Dodiuk-Gad RP, Chung WH, Valeyrie-Allanore L, Shear NH. Stevens-Johnson syndrome and toxic epidermal necrolysis: an update. Am J Clin Dermatol. 2015;16(6):475-93.

21. Mockenhaupt M. The current understanding of Stevens-Johnson syndrome and toxic epidermal necrolysis. Expert Rev Clin Immunol. 2011;7:803-13. https://doi.org/10.1586/eci.11.66 (quiz 814-5).

22. Sehgal VN, Srivastava G. Toxic epidermal necrolysis (TEN) Lyell's syndrome. J Dermatolog Treat. 2005;16:278-86.

23. Baroni A, Ruocco E. Lyell's syndrome. Skinmed. 2005;4:221-5.

24. Sekula P, Dunant A, Mockenhaupt M, Naldi L, Bouwes Bavinck JN, Halevy S, Kardaun S, Sidoroff A, Liss Y, Schumacher M, Roujeau JC, RegiSCAR study group. Comprehensive survival analysis of a cohort of patients with Stevens-Johnson syndrome and toxic epidermal necrolysis. J Invest Dermatol. 2013;133(5):1197-204.

25. Peter JG, Lehloenya R, Dlamini S, et al. Severe delayed cutaneous and systemic reactions to drugs: a global perspective on the science and art of current practice. J Allergy Clin Immunol Pract. 2017;5(3):547-63. https://doi.org/10.1016/j.jaip.2017.01.025.

26. Lalosevic J, Nikolic M, Gajic-Veljic M, Skiljevic D, Medenica L. Stevens-Johnson syndrome and toxic epidermal necrolysis: a 20-year single-center experience. Int J Dermatol. 2015;54(8):978-84.

27. Sousa-Pinto B, Araújo L, Freitas A, Correia O, Delgado L. Stevens-Johnson syndrome/toxic epidermal necrolysis and erythema multiforme drug-related hospitalisations in a national administrative database. Clin Transl Allergy. 2018;8:2. https://doi. org/10.1186/s13601-017-0188-1.
28. Valeyrie-Allanore L, Sassolas B, Roujeau JC. Drug-induced skin, nail and hair disorders. Drug Saf. 2007;30(11):1011-30 (Review. PubMed PMID: 17973540).

29. Sessa M, Rossi C, Mascolo A, Grassi E, Fiorentino S, Scavone C, Reginelli A, Rotondo A, Sportiello L. Suspected adverse reactions to contrast media in Campania Region (Italy): results from 14 years of post-marketing surveillance. Expert Opin Drug Saf. 2015;14:1341-51. https://doi.org/10.1517/14740338.2015.10673 01.

30. Guideline on good pharmacovigilance practices (GVP). Module VI. https://www.ema.europa.eu/en/documents/regulatory-proce dural-guideline/guideline-good-pharmacovigilance-practices-gvpmodule-vi-collection-management-submission-reports_en.pdf. Accessed 01 Aug 2019.

31. ICH Topic E 2. A-clinical safety data management: definitions and standards for expedited reporting. https://www.ema.europ a.eu/en/documents/scientific-guideline/international-conference -harmonisation-technical-requirements-registration-pharmaceut icals-human-use_en-15.pdf. Accessed 01 Aug 2019.

32. Luk AJ, Simkin PA. Epidemiology of hyperuricemia and gout. Am J Manag Care. 2005; 11:S435-42 (quiz S465-8).

33. Ramirez MEG, Bargman JM. Treatment of asymptomatic hyperuricemia in chronic kidney disease: a new target in an old enemy-A review. J Adv Res. 2017;8:551-4. https://doi. org/10.1016/j.jare.2017.04.006.

34. Ferrajolo C, Sultana J, Ientile V, Scavone C, Scondotto G, Tari M, Trifirò G, Rossi F, Capuano A. Gender differences in outpatient pediatric drug utilization: a cohort study from Southern Italy. Front Pharmacol. 2019;10:11. https://doi.org/10.3389/fphar .2019.00011.

35. Sportiello L, Rafaniello C, Sullo MG, Nica M, Scavone C, Bernardi FF, Colombo DM, Rossi F. No substantial gender differences in suspected adverse reactions to ACE inhibitors and ARBs: results from spontaneous reporting system in Campania Region. Expert Opin Drug Saf. 2016;15:101-7.

36. Scavone C, Sportiello L, Sullo MG, Ferrajolo C, Ruggiero R, Sessa M, Berrino PM, di Mauro G, Berrino L, Rossi F, Rafaniello C, Capuano A, BIO-Cam Group. Safety Profile of Anticancer and Immune-Modulating Biotech Drugs Used in a Real World Setting in Campania Region (Italy): BIO-Cam Observational Study. Front Pharmacol. 2017;8:607. https://doi. org/10.3389/fphar.2017.00607.

37. Scavone C, Rafaniello C, Brusco S, Bertini M, Menditto E, Orlando V, Trama U, Sportiello L, Rossi F, Capuano A. Did the new Italian law on mandatory vaccines affect adverse event following immunization's reporting? A Pharmacovigilance study in Southern Italy. Front Pharmacol. 2018;9:1003. https://doi. org/10.3389/fphar.2018.01003.

38. Ward KE, Archambault R, Mersfelder TL. Severe adverse skin reactions to nonsteroidal antiinflammatory drugs: a review of the literature. Am J Health Syst Pharm. 2010;67:206-13. https://doi. org/10.2146/ajhp080603.

39. Nguyen KD, Tran TN, Nguyen MT, Nguyen HA, Nguyen HA Jr, Vu DH, Nguyen VD, Bagheri H. Drug-induced Stevens-Johnson syndrome and toxic epidermal necrolysis in vietnamese spontaneous adverse drug reaction database: a subgroup approach to disproportionality analysis. J Clin Pharm Ther. 2019;44:69-77. https://doi.org/10.1111/jcpt.12754.

40. Ordoñez L, Salgueiro E, Jimeno FJ, Manso G. Spontaneous reporting of Stevens-Johnson syndrome and toxic epidermal necrolysis associated with antiepileptic drugs. Eur Rev Med Pharmacol Sci. 2015;19(14):2732-7.

41. Zhang C, Van DN, Hieu C, Craig T. Drug-induced severe cutaneous adverse reactions: Determine the cause and prevention. Ann Allergy Asthma Immunol. 2019. https://doi.org/10.1016/j. anai.2019.08.004. 
42. Agier MS, Boivin N, Maruani A, Giraudeau B, Gouraud A, Haramburu F, Jean Pastor MJ, Machet L, Jonville-Bera AP. Risk assessment of drug-induced drug reaction with eosinophillia and systemic symptoms (DRESS) syndrome: a disproportionality analysis using the French Pharmacovigilance Database. Br J Dermatol. 2016;175(5):1067-9. https://doi.org/10.1111/ bjd.14649.

43. Taghvaye Masoumi H, Hadjibabaie M, Zarif-Yeganeh M, Arasteh O. Exacerbation of allopurinol-induced drug reaction with eosinophilia and systemic symptoms by teicoplanin: a case report. J Clin Pharm Ther. 2017;42(5):642-5. https://doi. org/10.1111/jcpt.12556.

44. Waseem H, Inayat F, Abduraimova M, Kamholz S. Allopurinolinduced drug reaction with eosinophilia and systemic symptoms syndrome: a cause of acalculous cholecystitis? Cureus. 2017;9(8):e1569. https://doi.org/10.7759/cureus.1569.

45. Menter T, Tzankov A. Drug Reaction, Eosinophilia, and Systemic Symptoms (DRESS) syndrome associated with allopurinol leading to acute necrotizing eosinophilic myocarditis and death due to papillary muscle rupture. J Allergy Clin Immunol Pract. 2016;4(6):1262-4. https://doi.org/10.1016/j. jaip.2016.07.005.

46. Lien YH, Logan JL. Cross-reactions between allopurinol and febuxostat. Am J Med. 2017;130(2):e67-8. https://doi. org/10.1016/j.amjmed.2016.08.042.

47. Stamp LK, Day RO, Yun J. Allopurinol hypersensitivity: investigating the cause and minimizing the risk. Nat Rev Rheumatol. 2016;12:235-42.

48. Kim SC, Newcomb C, Margolis D, Roy J, Hennessy S. Severe cutaneous reactions requiring hospitalization in allopurinol initiators: a population-based cohort study. Arthritis Care Res (Hoboken). 2013;65:578-84. https://doi.org/10.1002/acr.21817.

49. Kang MG, Sohn KH, Kang DY, Park HK, Yang MS, Lee JY, Kang HR. Analysis of individual case safety reports of severe cutaneous adverse reactions in Korea. Yonsei Med J. 2019;60:208-15. https ://doi.org/10.3349/ymj.2019.60.2.208.

50. Gupta SS, Sabharwal N, Patti R, Kupfer Y. Allopurinol-induced Stevens-Johnson syndrome. Am J Med Sci. 2019;357:348-51. https://doi.org/10.1016/j.amjms.2018.11.018.

51. Diphoorn J, Cazzaniga S, Gamba C, Schroeder J, Citterio A, Rivolta AL, Vighi GD, Naldi L, REACT-Lombardia study group. Incidence, causative factors and mortality rates of Stevens-Johnson syndrome (SJS) and toxic epidermal necrolysis (TEN) in northern Italy: data from the REACT registry. Pharmacoepidemiol Drug Saf. 2016;25:196-203. https://doi.org/10.1002/pds.3937.

52. Wolfson AR, Zhou L, Li Y, Phadke NA, Chow OA, Blumenthal KG. Drug reaction with eosinophilia and systemic symptoms (DRESS) syndrome identified in the electronic health record allergy module. J Allergy Clin Immunol Pract. 2019;7(2):633-40. https://doi.org/10.1016/j.jaip.2018.08.013.

53. Thammakumpee J, Yongsiri S. Characteristics of toxic epidermal necrolysis and Stevens-Johnson syndrome: a 5-year retrospective study. J Med Assoc Thai. 2013;96(4):399-406.

54. Inácio $\mathrm{P}$, Cavaco A, Airaksinen $\mathrm{M}$. The value of patient reporting to the pharmacovigilance system: a systematic review. Br J Clin Pharmacol. 2017;83(2):227-46. https://doi.org/10.1111/bcp.13098.

55. Rodríguez-Martín S, Martín-Merino E, Lerma V, Rodríguez-Miguel A, González O, González-Herrada C, Ramírez E, Bellón T, de Abajo FJ. Incidence of Stevens-Johnson syndrome/toxic epidermal necrolysis among new users of different individual drugs in a European population: a case-population study. Eur J Clin Pharmacol. 2019;75:237-46. https://doi.org/10.1007/s00228-018-2569-3.

56. Høieggen A, Alderman MH, Kjeldsen SE, Julius S, Devereux RB, De Faire U, Fyhrquist F, Ibsen H, Kristianson K, LederballePedersen O, Lindholm LH, Nieminen MS, Omvik P, Oparil S, Wedel H, Chen C, Dahlöf B, LIFE Study Group. The impact of serum uric acid on cardiovascular outcomes in the LIFE study. Kidney Int. 2004;65:1041-9.

57. Wannamethee SG, Papacosta O, Lennon L, Whincup PH. Serum uric acid as a potential marker for heart failure risk in men on antihypertensive treatment: the British Regional Heart Study. Int J Cardiol. 2018;252:187-92. https://doi.org/10.1016/j.ijcar d.2017.11.083.

58. Ben Salem C, Slim R, Fathallah N, Hmouda H. Drug-induced hyperuricaemia and gout. Rheumatology (Oxford). 2017;56:67988. https://doi.org/10.1093/rheumatology/kew293.

59. Atzori L, Pinna AL, Mantovani L, Ferreli C, Pau M, Mulargia M, Aste N. Cutaneous adverse drug reactions to allopurinol: 10 year observational survey of the dermatology department-Cagliari University (Italy). J Eur Acad Dermatol Venereol. 2012;26(11):1424 30. https://doi.org/10.1111/j.1468-3083.2011.04313.x.

60. Pérez-Jover V, Mira JJ, Carratala-Munuera C, Gil-Guillen VF, Basora J, López-Pineda A, Orozco-Beltrán D. Inappropriate use of medication by elderly, polymedicated, or multipathological patients with chronic diseases. Int J Environ Res Public Health. 2018. https://doi.org/10.3390/ijerph15020310.

61. Yang SC, Hu S, Zhang SZ, Huang JW, Zhang J, Ji C, Cheng B. The Epidemiology of Stevens-Johnson Syndrome and Toxic Epidermal Necrolysis in China. J Immunol Res. 2018;2018:4320195. https://doi.org/10.1155/2018/4320195.

62. Chiou CC, Yang LC, Hung SI, Chang YC, Kuo TT, Ho HC, Hu S, Hong HS, Chung WH. Clinicopathological features and prognosis of drug rash with eosinophilia and systemic symptoms: a study of 30 cases in Taiwan. J Eur Acad Dermatol Venereol. 2008;22:1044 9. https://doi.org/10.1111/j.1468-3083.2008.02585.x.

63. Lerch M, Mainetti C, Terziroli Beretta-Piccoli B, Harr T. Current perspectives on Stevens-Johnson syndrome and toxic epidermal necrolysis. Clin Rev Allergy Immunol. 2018;54:147-76. https:// doi.org/10.1007/s12016-017-8654-z.

64. Kumari R, Timshina DK, Thappa DM. Drug hypersensitivity syndrome. Indian J Dermatol Venereol Leprol. 2011;77:7-15. https ://doi.org/10.4103/0378-6323.74964.

65. Arellano F, Sacristán JA. Allopurinol hypersensitivity syndrome: a review. Ann Pharmacother. 1993;27(3):337-43 (Review. PubMed PMID: 8453174).

66. Tas S, Simonart T. Management of drug rash with eosinophilia and systemic symptoms (DRESS syndrome): an update. Dermatology. 2003;206:353-6.

67. Lee HY, Ariyasinghe JT, Thirumoorthy T. Allopurinol hypersensitivity syndrome: a preventable severe cutaneous adverse reaction? Singap Med J. 2008;49:384-7.

68. Mockenhaupt M, Schöpf E. Epidemiology of drug-induced severe skin reactions. Semin Cutan Med Surg. 1996;15:236-43.

69. Strom BL, Carson JL, Halpern AC, Schinnar R, Snyder ES, Shaw M, Tilson HH, Joseph M, Dai WS, Chen D, et al. A populationbased study of Stevens-Johnson syndrome. Incidence and antecedent drug exposures. Arch Dermatol. 1991;127:831-8.

70. Schneck J, Fagot JP, Sekula P, Sassolas B, Roujeau JC, Mockenhaupt M. Effects of treatments on the mortality of StevensJohnson syndrome and toxic epidermal necrolysis: a retrospective study on patients included in the prospective EuroSCAR Study. J Am Acad Dermatol. 2008;58:33-40.

71. Arantes LB, Reis CS, Novaes AG, Carvalho MR, Göttems LBD, Novaes MRCG. Stevens-Johnson syndrome and toxic epidermal necrolysis: epidemiological and clinical outcomes analysis in public hospitals. An Bras Dermatol. 2017;92:661-7. https://doi. org/10.1590/abd1806-4841.20176610.

72. Fallon MJ, Heck JN. Fatal Stevens-Johnson syndrome/toxic epidermal necrolysis induced by allopurinol-rituximab-bendamustine therapy. J Oncol Pharm Pract. 2015;21:388-92. https://doi. org/10.1177/1078155214533368. 
73. Pennell DJ, Nunan TO, O'Doherty MJ, Croft DN. Fatal StevensJohnson syndrome in a patient on captopril and allopurinol. Lancet. 1984;1:463.

74. Coutellier P. Delgrange B [Fatal toxic epidermolysis following administration of allopurinol]. Acta Clin Belg. 1989;44:196-8.

75. Ranu H, Jiang J, Ming PS. A case series of allopurinol-induced toxic epidermal necrolysis. Indian J Dermatol. 2011;56:74-6. https://doi.org/10.4103/0019-5154.77557.

76. Fang B, Song Y, Ma J, Zhao RC. Severe epidermal necrolysis after Bortezomib treatment for multiple myeloma. Acta Haematol. 2007;118:65-7.
77. Watanabe Y, Matsukura S, Isoda Y, Morita A, Aihara M, Kambara T. A case of toxic epidermal necrolysis induced by allopurinol with human herpesvirus-6 reactivation. Acta Derm Venereol. 2013;93:731-2. https://doi.org/10.2340/00015555-1610.

78. Aversano MG, Schroeder J, Citterio A, et al. Levofloxacin induced Stevens-Johnson syndrome/toxic epidermal necrolysis overlap syndrome: case reports. Clin Transl Allergy. 2014;4:P91. https:// doi.org/10.1186/2045-7022-4-S3-P91.

79. Carnovale C, Venegoni M, Clementi E. Allopurinol overuse in asymptomatic hyperuricemia: a teachable moment. JAMA Intern Med. 2014;174:1031-2. https://doi.org/10.1001/jamaintern med.2014.1427. 